\title{
Contextual Influences on Child Feeding in Two South Asian Immigrant Groups
}

\author{
Alison Karasz ${ }^{1,{ }^{*}}$, Margia Shiriti ${ }^{1}$, Nilifa DeSilva ${ }^{1}$, Afrida Khurshid ${ }^{1}$, Karen Bonuck ${ }^{1}$ and \\ Usha Ramachandran ${ }^{2}$
}

${ }^{1}$ Department of Family and Social Medicine, Albert Einstein College of Medicine, 1300 Morris Park Blvd, Bronx NY 10461, USA

${ }^{2}$ Department of Pediatrics, Robert Wood Johnson School of Medicine, 89 French St. New Brunswick, NJ 08901, USA

\begin{abstract}
Child obesity is a major health disparity, with low-income communities bearing a disproportionate burden of disease. Although the powerful influence of socio-economic status on child diet and feeding practices is well established, its local contextual mechanisms are not necessarily well understood. This study used a qualitative comparative design to explore the socio-cultural context of child feeding ethnically similar but economically diverse immigrant families. Seventeen in-depth qualitative interviews conducted with affluent and low-income immigrant mothers from the South Asian subcontinent. We sought to explore potential contextual influences on maternal feeding practices, including: maternal beliefs and values, patterns of help and information seeking, family and household, and impacts of the chronosystem - the role of memory and life transitions. Our findings help to explain mechanisms underlying SES disparities in child obesity in this group, and maybe helpful in designing tailored interventions aimed at reducing these disparities.
\end{abstract}

Keywords: Health disparities, contextual features, South Asians, immigrant health, child obesity, feeding practices.

\section{INTRODUCTION}

\subsection{Background}

Childhood obesity is a major health disparity in the United States, with low income and ethnic minority communities bearing much of the burden of the disease. Key factors in this health disparity are child diet and feeding practices. Children from low-income families consume more fried, processed foods, sweets, and sweetened beverages than children in affluent families. Moreover, low-income mothers are more likely to engage in risky feeding practices such as prolonged bottle feeding, early introduction of solids, and an authoritarian feeding style [1, 2].

Social-ecological models have been widely recommended as a guide for developing public health programs, and it is widely understood that early childhood feeding practices are deeply embedded in a social context [3-5]. Nonetheless, most early childhood obesity interventions, like health promotion interventions in general, continue to focus on individual choice, cognition, and behavior [6, 7-9].

This approach is particularly problematic in the context of health disparities such as child obesity, in which influential structural factors-precisely, socio-

*Address correspondence to this author at the Department of Family and Social Medicine, Albert Einstein College of Medicine, 1300 Morris Park Blvd, Bronx NY 10461, USA; Tel: 7184308756;

E-mail: Alison.Karasz@Einstein.yu.edu economic status--exert a constraining influence on individual choice. To develop intervention models that extend beyond individual choice and cognition, a better understanding is needed of the types of contextual mechanisms through which socioeconomic status exerts influence. To date, there has been relatively little research on mechanisms through which socioeconomic status influences maternal feeding practices $[10,11]$.

\subsection{The Present Study}

This qualitative study examined SES influences on the household context of child feeding among South Asian (SA) immigrants in the US, in preparation for a large scale feeding intervention designed to reduce child obesity risk behaviors among low-income SA mothers. One of the fastest-growing immigrant groups in the United States, South Asians are also one of the most diverse. SA communities in the North East of the United States include both highly educated, affluent families employed in the professions and the technology industries, as well as more low-income workingclass families living in dense urban enclaves [12].

Low-income SA children are at increased risk for childhood obesity $[13,14]$. Identified risk factors include child feeding practices, particularly parent-led or 'authoritarian' feeding [15-18], delayed weaning, and frequent intake of sweets and sweet drinks [18-23].

The study used a comparative design to contrast low and high-income mothers. Qualitative comparative 
designs can help to highlight key variables and expand the researcher's ability to draw inferences [24]. To maximize the strength of a comparative design, comparison groups should share characteristics yet differ on the key point of theoretical interest. Our study recruited SA immigrants from two economically diverse SA communities in the Greater New York Metropolitan region: the Central New Jersey suburbs, and a lowincome urban neighborhood in the Bronx, NY.

\section{METHODS}

\subsection{Sample and Recruitment}

We recruited affluent families from a suburban private pediatric practice near Princeton, New Jersey. The practice does not accept Medicaid. Low-income families were recruited from pediatric practices serving mostly Medicaid families in the Bronx, NY - the poorest congressional district in the United States. Though we did not have income criteria in selecting our sample, the differences between the two groups were marked. Seventeen affluent and low-income SA immigrant mothers of children aged six months to four years of age were recruited.

\subsection{Data Collection}

We designed an interview guide that was intended to explore both feeding practices and contextual influences. The guide was based on an adapted ecological model of risk for child obesity proposed by Zhou and Cheah [4]. Our variables included factors at the individual level-maternal beliefs, values, and practices related to child health and feeding; the health system level-interactions with formal and informal caregivers and sources of child health information; the household level-influences of extended family members; and the level of the chronosystem--the influence of time, memory and life transitions.

After participating in informed oral consent, mothers were interviewed by phone. Interviews were conducted in the language of choice: mothers in suburban New Jersey preferred to be interviewed in English; Bronx urban mothers in Bengali. In keeping with standard qualitative interviewing techniques, participants were encouraged to tell their stories in their own words. Interviews were conducted by a bilingual Bengali and English speaking research assistant (the second author) and audiotaped. Bengali tapes were translated by the interviewer and transcribed into English. All participants received a $\$ 25$ honorarium. The study was approved by the Institutional Review Board of the Albert Einstein College of Medicine.

\subsection{Data Analysis}

We developed a brief prior coding scheme based on the literature and our knowledge of the topic for each of the two participant groups and revised it using an iterative process. Once the coding scheme was judged to fit the data, the authors coded the entire data set. Data were uploaded into NVivo 11, a qualitative data analysis program that facilitates the rapid organization and retrieval of thematically linked data. For this comparative analysis, we used matrix functions in NVivo to conduct group comparisons on feeding behaviors, beliefs and philosophies, information seeking, family and social context, and memories of the childhood food environment. As hypotheses emerged, we searched for confirming and disconfirming cases, occasionally contacting participants to ask for further information. As part of a 'member checking' process, the paper was shared with a group of stakeholders/collaborators, including pediatricians working with the community [25].

\section{RESULTS}

\subsection{Sample}

For a description of the sample, see Table 1. As expected, the two study groups differed dramatically in education, language, income, and immigration history.

Table 1: Description of the Sample

\begin{tabular}{|c|c|c|}
\hline & $\begin{array}{c}\text { Urban } \\
\mathbf{n = 9}\end{array}$ & $\begin{array}{c}\text { Suburban } \\
\mathbf{n = 8}\end{array}$ \\
\hline \hline Mean Number of Children & 2.3 & 1.6 \\
\hline \% Works Outside the Home & 11.1 & 50.0 \\
\hline Mean Years of Education & 13.5 & 17.7 \\
\hline Mean Years in US & 4.25 & 8.5 \\
\hline Mean Annual Income & $\$ 17,500$ & $\$ 165,000$ \\
\hline
\end{tabular}

\subsection{Contextual Influences}

\subsubsection{Influences at the Individual Level: Maternal Beliefs, Values, and Practices}

\subsubsection{Beliefs and Values}

We found that the two groups differed significantly concerning their values and concerns related to child health and development. Simply put, they worried 
about different things. Among low-income mothers, child growth and weight was the most significant concern. Most mothers in the low-income group concerned about their children's size, even when they received professional reassurance:

[At the] WIC office, they say that her height and weight are good. She is OK. Still, I am worried that my daughter is skinny and lightweight. If only she weighed a little bit more... her older brother is so fat!

When pediatricians expressed concerns about children's overweight, low-income mothers were often pleased to hear it:

The doctor said her weight is too high. (And what do you think?) She doesn't need to lose or gain. Her weight, by the grace of God, is really good. She's better than my other two children.

Though several affluent mothers also admitted that they wished their children were chubbier, overall, they were much less concerned about their children's weight than low-income mothers. Among affluent mothers, concerns focused on developmental milestones. Affluent mothers were well aware of current medical guidelines related to feeding and development. They knew the recommended timing for weaning, selffeeding, toilet training, and other milestones. When asked if her three-year-old was still using a bottle, an affluent mother noted:

She is no longer having the bottle at all. No, oh my god, that would be a nightmare-because she's three! The bottle, no, I would be panicking!

By contrast, low-income mothers expressed little concern about milestones. None of the mothers in the low-income group indicated that she was worried about her child's cognitive and physical development. Lowincome mothers seemed much less likely to promote maturation or autonomy among their children. On the contrary, their feeding practices reflected a philosophy of child-rearing that emphasized intensive nurturing, "babying" and control, as if seeking a prolongation of infancy.

\subsubsection{Feeding Practices}

Low income (but not affluent) mothers engaged in bottle feeding far beyond 18 months as recommended by AAPD guidelines [26]. It was not uncommon for mothers to report that their school-aged children still used a bottle. Though they sometimes complained about this, mothers expressed little anxiety.

[My son is] about to turn 6, he's already 5 years old. But he will only drink milk from a bottle! I tried to give him a straw, but he refuses. . . (laughs)

Mothers often breastfed their children well into the preschool years.

In our culture, we are meant to stop breastfeeding at 2 years, or else Islam does not approve it. But I can't get [my three-year-old] to stop. She still wants it from me. Alongside the bottle, she will have breastmilk when we lie down. Maybe 2 or 3 times [per day]. And now at night she will want to drink it while she is sleeping. And when she wakes up in the morning, it's a must.

Low-income mothers typically reported parent-led feeding practices [27]. Often, mothers actively fed their children to a relatively advanced age.

When did [middle child] begin picking up food with his own hands and feeding himself? Oh, don't even ask me about that. He started when he was 5 years old. And my oldest son is now 10 years old. I still have to feed him. . . Yes, still now! If I don't feed him today, he'll go the entire day without eating.

In keeping with the theme of prolonging infancy, low-income mothers also made extensive use of pureed foods. Often they would prepare a dishkhichuri, a textured mix of lentils, rice, and vegetables-and puree it in the blender before feeding it to a toddler or preschool child. Biscuits, meats, fish, eggs, and bread were often soaked in liquid and beaten into a paste, then diluted with water or milk and fed via bottle or spoon. Many mothers fed their children a diet heavy in traditional milk-based sweet puddings, often regarded as an ideal food for young children.

Perhaps as a consequence of these practices, many toddlers and preschoolers showed a marked aversion to solid foods. Mothers reported many examples of delayed swallowing and chewing. 
When it comes to solid food...he (6-yearold sibling of index child) still gives me a hard time with solid food. He'll only drink milk or eat payesh (milk pudding).

All her teeth grew in, but [my 18-monthold] doesn't eat anything with her teeth. I have to make everything very soft to feed her. She doesn't chew. She is not able to eat solid foods yet. Eating...she will rip it up with her teeth and spit it out. I don't know why she doesn't chew.

Almost all low-income mothers in the sample described food aversion and refusal.

And when you sit with him for 2 hours, do you continuously try to make him eat? He sits there with the food in his mouth! I give him one spoonful, and he sits there for a long time. He doesn't swallow for $10-15$ minutes!

It takes him about half an hour to eat even if he watches TV. And the days when he does not want to eat, he will keep the food in his mouth and sit there. . .

Mothers made intensive efforts to overcome children's resistance.

Maybe I will take him near the sink and show him the water. He will touch the water and then take a little bit of food into his mouth. Now he understands, so I give him the iPad or phone or cartoon. So he will eat as he watches cartoons.

Force-feeding was common:

When I feed him khichuri or cereal, or a 4 oz. yogurt, or 6 oz., I force him. By force, I mean...his face... he is able to say "no". He says, "no no". He shows that he does not want it. But I finish [it]. If he says "no", then I will sit there for 30 seconds. Then when he continues to draw or scribble, l'll put it in his mouth, and he'll swallow.

I feed her while she watches TV. I give her milk, banana, whatever is there, formula or rice. If she doesn't want to eat, I force her. Every morning I feed her milk. Whether she wants to or not...I forcefully give her the milk.
With older children, mothers frequently used threats:

If I try to feed him rice, he gives me a hard time. He keeps saying, "I don't want to eat it...I don't want to eat it." I have to make up a lot of things to get him to eat. For example, I'll tell him that I will take him to the doctor who will give him a shot if he doesn't eat.

As noted, parent-controlled feeding behaviors were embedded in values related to the prolongation of infancy and the virtue of intensive mothering. Many low-income mothers were aware of the medical advice that children should eat only when they are hungry. To reconcile this awareness with their own values and practices, several posited a notion of 'inner hunger'-a hunger that young children did not know they felt. When the interviewer, a young unmarried woman, asked one participant how she could tell that her child was hungry when he was actively refusing food, the mother laughed, implying that only a mother would be able to understand.

I saw that she had not eaten anything. Allday. She must be suffering, right? (How are you able to tell that she is suffering?) [Laughs] You will understand when you become a mom! All moms will be able to understand that this child hasn't eaten...so....yeah. She's suffering. She's hungry. A mother's heart knows.

\subsubsection{Influences at the Health System Level}

As expected, affluent mothers were much more likely to turn to professional advice or other sources of technical help with child feeding than low-income mothers. At the same time, the latter were more likely to turn to traditional sources of authority, especially elderly family members. Affluent mothers frequently referenced their pediatricians as sources of advice on child health, weight, and feeding. Wealthy mothers were also much more likely to seek out information through online articles, internet search engines, or phone apps. Unlike low-income mothers, they tended to deliberately 'weigh' information from different sources and synthesize this information in determining their own course of action:

"But you know, like it is my first child, so [laughs] I'm whatever I know about child feeding or whatever l'm implementing is 
based on whatever research l've conducted, you know, a little bit of input from my baby's pediatrician and my mom and my mother-in-law and everything like that."

Though low-income mothers were less likely to reference medical advice as an influence, we did not find that these mothers were unaware of such advice. In fact, the marked differences in child feeding beliefs and practices across the two study groups did not result mainly from a knowledge deficit in the lowincome group. Several mothers who fed their children large quantities of sweet foods knew that the 'doctors' advice' was to avoid such foods. Some mothers seemed to struggle with the contradiction between traditional South Asian concepts of a nutritious child diet, which includes an emphasis on milk and traditional milk-based sweets and puddings, and modern health concepts. When asked: "Is it good to give sweets to kids?" one mother mused:

I think it's good to give kids sweet foods. The dishes we eat at home--our Bengali foods like payesh [sweet milk puddings] . . . They are good for health.

After a moment of further thought, she noted:

[But] actually eating sweets, is not good for health and it's also not good for the teeth if you eat sweets. . what is good or bad, I am not really understanding.

The groups differed sharply in their use of advice and counsel from family members. In contrast to lowincome mothers, few affluent mothers referenced family members as an important source of information on child-rearing and feeding. Affluent mothers reported receiving advice from elders, but they seemed less likely to be influenced by such advice. Affluent mothers seemed to feel that child feeding decisions should be made by parents-not by family elders.

I just don't compare myself or my feeding habits to anybody else in our family. [Laughs] I mean [my husband and I] have our own habits. We know what's needed for [our children], and we stick to it.

The one thing that we had told both our parents was that the way kids are taken care of by doctors here in the US is a little bit different than it is in India, right? So if anything goes wrong with the baby, we have to explain what happened to the doctor. And we told them that we feel that it's just easier if you follow what the doctor is saying. ... And they understood that. ...

Low-income mothers viewed their family elders in a very different light. These mothers described constantly conferring with elders about child feeding. Low-income mothers saw their family elders as authorities on child care and feeding.

[As mothers], we don't understand things [before having a child]. Although we may know a lot of information, but how to handle everything after giving birth to the child--sometimes we are not able to understand it all.

I was not able to breastfeed...so [my mother] taught me that. She taught me how to lay [the baby] down properly. She taught me how to bathe her. I didn't know anything. I learned everything from my mom. How to raise a child well, and how to keep them nicely.

I received most of the advice from my mother. At 6 months, when I started giving more normal foods, I would receive advice from my mom about how to take care of them, food, and all.

Low-income mothers seemed to feel that child feeding decisions were a family matter and that those with greater seniority should have influence on such decisions. When family elders were not available, mothers relied on older friends or neighbors for advice and support. One mother, living alone with her husband in a remote town far from her family, had been told by a pediatrician that her son should lose weight:

The doctor gave me a chart. I saw that my son weighed [more than he was supposed to weigh.]

She wondered if she should follow the physician's advice. But her neighbors, who provided daily support, advice, and fresh milk to this young mother, reassured her:

And the neighbors. . cared for me a lot. [They] would say, "No-- your son looks very nice. He's very chubby." 
The mother concluded:

It's true he was very chubby, and there was no problem with his health.

\subsubsection{Influences at the Household/Extended Family System Level}

We have noted that low and high income mothers differed in the degree to which they sought advice from family members. Among affluent mothers, grandparents were supportive of mothers' decisions:

So we didn't really have trouble with our parents. They were very easy-they would defer to us or defer to what the doctor was saying. They didn't force us with anything.

The situation was very different for low-income mothers. Many low-income mothers reported receiving frequent criticism from relatives regarding their feeding practices and their children's weight.

My family members tell me... how do I say this [laughs]...they say I am not a good mom. . . My mom says it and others say it when I visit their house but don't bring special food from home for my children. ... But why must I feed a specific food? I can feed an alternative at any time. Kids should be used to variety.

If we have just come back from somewhere with the kids--three kids--I have to feed all of them because they are all hungry. So I might eat first... Because I know that I am going to have to spend a lot of time feeding them. . I want to finish eating quickly and then feed them with a calm state of mind. [But then] everyone in the house says to me, "what kind of mom are you?"

Family members frequently criticized mothers about their children's weight:

My older sister would say, "Oh my, how did he end up being so lightweight?!" My mom would also express her disappointment. [But] my child was actually really tall ... he was born very tall and didn't have any meat on his body.

While the criticism of close natal relatives was painful, the criticism of in-laws was more toxic. In extended families, in which wives struggle for the favor of powerful affines and must play family politics [28-30], child feeding and child weight can become grist for the malicious gossip mill.

[My in-laws] will call my kids 'too thin' [shukna]. The way they say it is...they twist their words. They will beat around the bush and say that the kids are too thin and suggest that the reason is that they are not well taken care of. It's a purposeful jab at me without clearly saying so.

\subsubsection{Influences at the Level of Memory and Experience}

We found that the two study groups differed in their perceptions of both their childhood and present food environments. Affluent mothers described positive memories of food and eating in their Indian childhoods. Their food 'story' involved a transition from a healthy food environment in their Indian childhoods, to the hazardous industrialized food environment of the United States.

They just said you have to eat whatever is made at home. Nothing special is going to be made for you. So you have to eat all of the vegetables. So that's what I'm trying with [my son].

Yeah, here [in the US] one thing is that the packaged food is a little bit too much. We don't find that much use of packaged food for kids back in India. So that is one thing that I don't think it's very good for kids.

Affluent mothers were wary of processed foods. Almost all of the affluent mothers felt guilty when they fed packaged food to their children.

I'm a working mom, so sometimes it gets tough for me. I won't say l'Il never use the packaged stuff, but [only] if I have to.

Affluent mothers viewed the American food environment as a source of peril:

It's not like every day let her have a cupcake ... or on my god, then there would be too much sugar in the house.

(What's your personal opinion about adding sugars to foods?) I think it's poison. If you're doing that you're definitely putting poison in the food. . . It's 
very hard to escape added sugars. ... But yeah, I definitely think it's poison. It's like the worst thing you can do is add sugar.

Low-income mothers presented a very different picture of their childhood food environment. Mothers in this group recounted that caretakers had taken a laissez-faire approach to feeding them -allowing them even as young children to be fed by siblings, or left to feed themselves. Mealtimes were irregular and unsupervised.

My mom did not spend time on us the way I am doing now. She would sit us down, and that was it. My mom said we fed ourselves with our own hands. We ran around, studied, everything....we generally did everything on our own.

The contrast between low-income mothers' current feeding practices and the laissez-faire approach of their own mothers was marked.

From what you remember, were you fed on a schedule? No, we didn't have that in my time. If I was hungry, I ate. Our mothers were not this anxious about feeding us. They would give us food, and we would eat it. Nowadays, I struggle a lot with my kids. If my son is hungry, he will remain hungry and won't eat. When I chase my kids around to feed them, my mom would tell me, "I didn't struggle this much with you guys. You all would eat well on your own."

When we asked low-income mothers to explain these differences, many described the atmosphere of scarcity and constrained choices that their own mothers had endured. As daughters-in-law in large extended families, these mothers were required to wait on their in-laws and husbands, duties which took away from their ability to care for their own children.

Mothers weren't able to give undivided attention to their kids. There were elders in the family...they had to struggle. ... [Also] during [our mothers'] time the husbands were not as active in terms of sharing responsibilities. Mothers had to raise the kids on their own.

Financial struggles had limited their mothers' abilities to provide to their children.
[In Bangladesh] Mothers aren't just stressed out about feeding, and they also feel tension with regards to several other things. How much the child is growing. The child's future education. Depending on the household income... [A mother] has to consider how she will manage everything in the home, including raising her child on that budget. Often times, those are bigger concerns than feeding.

Low-income mothers contrasted the food scarcity that marked their own childhoods, to the safety, purity, abundance, affordability, and quality of food in the US context. Packaged infant and child foods, expensive in Bangladesh, were affordable in the US.

[In Bangladesh], income is a greater factor. Even if the income is medium, it may not be enough to purchase certain items to feed. A person has to think before purchasing. The prices do not align with the incomes. But here it's not like that. We are able to purchase the foods easily. The things that we want, we are able to access here. It's not the same in Bangladesh.

Even if our income is low [here] we are able to buy a lot of things. . There are a lot of ready-made foods available. Like pudding, baby food, noodles. We are able to give these to the kids quite soon.

\section{DISCUSSION}

We explored feeding behaviors and contextual influences on feeding in two economically diverse groups of SA immigrant mothers. Feeding practices known to contribute to childhood obesity, such as delayed weaning, liquefying foods, frequent feeding of sweetened foods and beverages, delayed self-feeding, and force-feeding, were more common in the lowincome group than in the affluent group. Our analysis helps to explain how contextual features--cultural values around child health and development, family network influences, help-seeking patterns, and contrasting life experiences-strongly influenced these practices.

\subsection{Contextual Influenced on Low-Income Mothers}

Research has found that parental memories of childhood hunger and deprivation are associated with risky feeding child feeding practices [31]. The childhood 
memories of feeding that we elicited in our interviews with low-income mothers did not describe hunger-at least, not explicitly. Yet many mothers described being fed haphazardly as children, without significant parental supervision. Overall, their accounts suggest households with constrained resources. Several of these mothers described how household duties, service to elders, and financial difficulties had preoccupied their own mothers, leaving them little time to devote to child feeding.

Ethnographic studies examining barriers to child nutrition among low-income families in South Asia have found that mothers report that the lack of both time and money are key factors in underfeeding [32]. Household work and the traditional burden of serving elders take away time mothers need to attend to their children's feeding [28, 33, 34]. Children of working mothers are often left with a neighbor, aged relative, or sibling during the day $[33,35,36]$. A common theme across studies is that disempowered mothers develop philosophies of child feeding that perhaps make deprivation more tolerable. Rural mothers in one study believed that children should not be 'fed' at all after an early age but should feed themselves. Mothers reported that young children who are fed all the time 'don't like it,' 'feel too full', 'have trouble digesting' and 'poop all the time' [37]. Another reported the belief among mothers that feeding children on a schedule or feeding large quantities can make them sick [33].

Among low-income mothers in our study, the contrast could not be more marked. Compared to the very low-income mothers described in the literature, and even to their own mothers, our low-income immigrant participants sought to 'prolong infancy' in their children through control, supervision, and forceful feeding. Living as housewives in nuclear families, with access to an abundance of food, and without the daily burden of waiting on in-laws, these mothers may feel that they should take advantage of their privileges by focusing their energies on feeding.

We also found that low-income mothers must cope with the realities of extended family life and the worrying power of gossip. Many participants reported criticism from relatives if they did not visibly devote themselves to intensive child feeding, or if their children did not seem to gain weight. In these families, a chubby child may represent the visible evidence of maternal virtue, while a slim child seems to reflect badly on the reputation of the whole family.

\subsection{Contextual Influences on Affluent Mothers}

Among affluent South Asian mothers, feeding practices seemed to reflect cultural and historical influences shaping values and practices that are common in other wealthy American groups. As Popkin and others have noted, western societies are passing through the fifth and final stage in the Nutrition Transition. At this stage, obesity has become a disease of poverty [38, 39], while the wealthy and elites adopt a careful, not to say wary, attitude towards food [40]. Concerns about overconsumption and preferences for 'natural' 'organic' and 'whole' foods have become common, and body habitus is altered to reflect the cultural value placed on slimness [41].

We also found that family elders played a much less influential role in child feeding decisions among affluent families, compared to low-income families. Research has shown that in immigrant families, grandparents' influence may predict childhood obesity as well as other nutrition-related diseases like childhood caries. Affluent mothers seemed to acknowledge a difference between their own views and those of their parents. But, perhaps because of their affluence and success, these mothers probably enjoy a higher status within their extended families. Indeed, they did not seem much concerned about criticism. The gossip mill, a form of social control in a traditional context, did not seem to threaten them. As a result, they made their own choices regarding child feeding and felt that their family members accepted their authority.

\section{CONCLUSION}

It is common in cross-cultural studies to conceptualize 'deviations' from modern biomedical advice as 'cultural beliefs' reflecting a lack of knowledge or education [42]; most health promotion interventions continue to emphasize educational interventions. Our results confirm that risky child feeding practices in an immigrant community cannot be attributed mainly to a lack of knowledge or education. Low-income mothers in the present study were aware of medical advice, but they sought to balance such information with traditional culture and values, as well as specific constraints on personal choice.

Results help to illustrate why child feeding interventions that focus mainly on the provision of information, particularly in the context of socioeconomic health disparities, are often unsuccessful. Our results suggest the need for creative new intervention 
approaches. Perhaps using peer and social network building strategies, which might strengthen healthy child feeding norms and provide social and instrumental support, might be a more valuable method for influencing behavior change.

\section{ACKNOWLEDGEMENT}

This study was funded by grant number MD01046001 from the National Institute of Minority Health and Health Disparities. The sponsor played no role in study design, data collection, data analysis, or the writing of this report.

\section{REFERENCES}

[1] Isong I, Dantas L, Gerard M, Kuhlthau K. Oral Health Disparities and Unmet Dental Needs among Preschool Children in Chelsea, MA: Exploring Mechanisms, Defining Solutions. Journal of Oral Hygiene \& Health 2014; 2.

[2] Cardel M, Willig AL, Dulin-Keita A, Casazza K, Beasley TM, Fernandez JR. Parental feeding practices and socioeconomic status are associated with child adiposity in a multi-ethnic sample of children. Appetite 2012; 58(1): 347-53. https://doi.org/10.1016/j.appet.2011.11.005

[3] Bolton KA, Kremer P, Hesketh KD, Laws R, Kuswara K, Campbell KJ. Differences in infant feeding practices between Chinese-born and Australian-born mothers living in Australia: a cross-sectional study. BMC pediatrics 2018; 18(1): 209. https://doi.org/10.1186/s12887-018-1157-0

[4] Zhou N, Cheah CS. Ecological risk model of childhood obesity in Chinese immigrant children. Appetite 2015; 90: 99107.

https://doi.org/10.1016/j.appet.2015.02.028

[5] Wutich A, McCarty C. Social networks and infant feeding in Oaxaca, Mexico. Matern Child Nutr 2008; 4(2): 121-35. https://doi.org/10.1111/j.1740-8709.2007.00122.x

[6] Golden SD, Earp JA. Social ecological approaches to individuals and their contexts: twenty years of health education \& behavior health promotion interventions. Health education \& behavior: the official publication of the Society for Public Health Education 2012; 39(3): 364-72. https://doi.org/10.1177/1090198111418634

[7] Holman D, Lynch R, Reeves A. How do health behaviour interventions take account of social context? A Literature Trend and Co-Citation Analysis 2018; 22(4): 389-410. https://doi.org/10.1177/1363459317695630

[8] Baum F, Fisher M. Why behavioural health promotion endures despite its failure to reduce health inequities. Sociol Health IIIn 2014; 36(2): 213-25. https://doi.org/10.1111/1467-9566.12112

[9] Davison KK, Birch LL. Childhood overweight: a contextual model and recommendations for future research. Obes Rev 2001; 2(3): 159-71. https://doi.org/10.1046/j.1467-789x.2001.00036.x

[10] Pak-Gorstein S, Haq A, Graham EA. Cultural Influences on Infant Feeding Practices. Pediatrics in Review 2009; 30(3): e11-e21.

https://doi.org/10.1542/pir.30-3-e11

[11] Pallan M, Parry J, Cheng KK, Adab P. Development of a childhood obesity prevention programme with a focus on UK South Asian communities. Prev Med 2013; 57(6): 948-54. https://doi.org/10.1016/j.ypmed.2013.08.025

[12] Asian, Pacific Islanders Health F. South Asians in the United States 2006. Contract No.: Report.
[13] Godson JH, Williams SA. Oral health and health related behaviours among three-year-old children born to first and second generation Pakistani mothers in Bradford, UK. Community Dental Health 1996; 13(1): 27.

[14] Cowin I, Emmett P, Team AS. Diet in a group of 18-monthold children in South West England, and comparison with the results of a national survey. J Hum Nutr Diet 2007; 20(3): 254-67.

https://doi.org/10.1111/j.1365-277X.2007.00772.x

[15] Gu C, Warkentin S, Mais LA, Carnell S. Ethnic differences in parental feeding behaviors in UK parents of preschoolers. Appetite 2017; 113: 398-404. https://doi.org/10.1016/j.appet.2017.03.001

[16] Olvera N, Power TG. Brief report: parenting styles and obesity in Mexican American children: a longitudinal study. Journal of Pediatric Psychology 2010; 35(3): 243-9.

https://doi.org/10.1093/jpepsy/jsp071

[17] Engle PL, Pelto GH. Responsive feeding: implications for policy and program implementation. J Nutr 2011; 141(3): 508-11.

https://doi.org/10.3945/in.110.130039

[18] Karasz A, Bonuck K. Reducing pediatric caries and obesity risk in South Asian immigrants: randomized controlled trial of common health/risk factor approach. BMC Public Health 2018; 18(1): 680 https://doi.org/10.1186/s12889-018-5317-9

[19] Kannan S, Carruth BR, Skinner J. Infant Feeding Practices of Anglo American and Asian Indian American Mothers. Journal of the American College of Nutrition 1999; 18(3): 279-86. https://doi.org/10.1080/07315724.1999.10718864

[20] Toh JY, Yip G, Han WM, Fok D, Low YL, Lee YS, et al. Infant Feeding Practices in a Multi-Ethnic Asian Cohort: The GUSTO Study. Nutrients 2016; 8(5).

https://doi.org/10.3390/nu8050293

[21] Momin SR, Chung KR, Olson BH. A qualitative study to understand positive and negative child feeding behaviors of immigrant Asian Indian mothers in the US. Matern Child Health J 2014; 18(7): 1699-710.

https://doi.org/10.1007/s10995-013-1412-9

[22] Martinson ML, McLanahan S, Brooks-Gunn J. Variation in child body mass index patterns by race/ethnicity and maternal nativity status in the United States and England. Matern Child Health J 2015; 19(2): 373-80. https://doi.org/10.1007/s10995-014-1519-7

[23] Bansal N, Ayoola OO, Gemmell I, Vyas A, Koudsi A, Oldroyd $\mathrm{J}$, et al. Effects of early growth on blood pressure of infants of British European and South Asian origin at one year of age: the Manchester children's growth and vascular health study. J Hypertens 2008; 26(3): 412-8. https://doi.org/10.1097/HJH.0b013e3282f3168e

[24] Karasz A, Singelis TM. Qualitative and Mixed Methods Research in Cross-cultural Psychology: Introduction to the Special Issue. J Cross Cult Psychol 2009; 40(6): 909-16. https://doi.org/10.1177/0022022109349172

[25] Giacomini MK, Cook DJ. Users' guides to the medical literature: XXIII. Qualitative research in health care A. Are the results of the study valid? Evidence-Based Medicine Working Group. JAMA 2000; 284(0098-7484; 3): 357-62.

https://doi.org/10.1001/jama.284.3.357

[26] AAPD. Guideline on Infant Oral Health Care 2014

[27] Baughcum AE, Burklow KA, Deeks CM, Powers SW, Whitaker RC. Maternal feeding practices and childhood obesity: a focus group study of low-income mothers. Arch Pediatr Adolesc Med 1998; 152(10): 1010-4. https://doi.org/10.1001/archpedi.152.10.1010

[28] Buckshee K. Impact of roles of women on health in India. International journal of gynaecology and obstetrics: the official organ of the International Federation of Gynaecology and Obstetrics 1997; 58(0020-7292; 1): 35-42. https://doi.org/10.1016/S0020-7292(97)02887-7 
[29] Rauf A. Rural women and the family: A study of a Punjabi village in Pakistan 1987; pp. 403-15. https://doi.org/10.3138/jcfs.18.3.403

[30] Karasz A. Marriage, Depression and Illness: Sociosomatic Models in a South Asian Immigrant Community. Psychology and Developing Societies 2005; 17(2): 161-80. https://doi.org/10.1177/097133360501700205

[31] Cheah CS, Van Hook J. Chinese and Korean immigrants' early life deprivation: an important factor for child feeding practices and children's body weight in the United States. Soc Sci Med 2012; 74(5): 744-52. https://doi.org/10.1016/j.socscimed.2011.10.040

[32] Affleck W, Pelto G. Caregivers' responses to an intervention to improve young child feeding behaviors in rural Bangladesh: a mixed method study of the facilitators and barriers to change. Soc Sci Med 2012; 75(4): 651-8. https://doi.org/10.1016/j.socscimed.2012.03.030

[33] Naila N, Nahar B, Lazarus M, Ritter G, Hossain M, Mahfuz $\mathrm{M}$, et al. "Those who care much, understand much." Maternal perceptions of children's appetite: Perspectives from urban and rural caregivers of diverse parenting experience in Bangladesh. Matern Child Nutr 2018; 14(1). https://doi.org/10.1111/mcn.12473

[34] Quazi SAG, Priti K, Umesh K, Nazli K, Shilpa G. Challenges and patterns of complementary feeding for women employment: A qualitative study from rural India. Research in Nutrition and Food Science 2016; 4(1): 48-53. https://doi.org/10.12944/CRNFSJ.4.1.06

[35] Faruque AS, Ahmed AM, Ahmed T, Islam MM, Hossain MI, Roy SK, et al. Nutrition: basis for healthy children and mothers in Bangladesh. Journal of Health, Population, and Nutrition 2008; 26(3): 325-39. https://doi.org/10.3329/jhpn.v26i3.1899
[36] Chaturvedi S, Ramji S, Arora NK, Rewal S, Dasgupta R, Deshmukh $\mathrm{V}$, et al. Time-constrained mother and expanding market: emerging model of under-nutrition in India. BMC Public Health 2016; 16: 632.

https://doi.org/10.1186/s12889-016-3189-4

[37] Chanchani D. Maternal and child nutrition in rural Chhattisgarh: the role of health beliefs and practices. Anthropol Med 2017; 1-17.

[38] Monteiro CA, Conde WL, Popkin BM. The burden of disease from undernutrition and overnutrition in countries undergoing rapid nutrition transition: a view from Brazil. Am J Public Health 2004; 94(3): 433-4. https://doi.org/10.2105/AJPH.94.3.433

[39] Monteiro CA, Moura EC, Conde WL, Popkin BM. Socioeconomic status and obesity in adult populations of developing countries: a review. Bull World Health Organ 2004; 82(12): 940-6.

[40] Popkin BM. Nutritional patterns and transitions. Population and Development Review 1993; 19(1): 138-57. https://doi.org/10.2307/2938388

[41] Karasz A, Dempsey $K$. Health seeking for ambiguous symptoms in two cultural groups: a comparative study. Transcult Psychiatry 2008; 45(3): 415-38. https://doi.org/10.1177/1363461508094674

[42] Brewis A, Gartin M. Biocultural construction of obesogenic ecologies of childhood: parent-feeding versus child-eating strategies. American Journal of Human Biology: the Official Journal of the Human Biology Council 2006; 18(2): 203-13. https://doi.org/10.1002/ajhb.20491 